\title{
Article \\ Understanding the Origin of Metal Gate Work Function Shift and Its Impact on Erase Performance in 3D NAND Flash Memories
}

\author{
Sivaramakrishnan Ramesh *(D), Arjun Ajaykumar, Lars-Åke Ragnarsson, Laurent Breuil, Gabriel Khalil El Hajjam, \\ Ben Kaczer, Attilio Belmonte, Laura Nyns, Jean-Philippe Soulié (D, Geert Van den bosch and Maarten Rosmeulen
}

Citation: Ramesh, S.; Ajaykumar, A.; Ragnarsson, L.-Å.; Breuil, L.; El Hajjam, G.K.; Kaczer, B.; Belmonte, A.; Nyns, L.; Soulié, J.-P.; Van den bosch, G.; et al. Understanding the Origin of Metal Gate Work Function Shift and Its Impact on Erase Performance in 3D NAND Flash Memories. Micromachines 2021, 12, 1084. https://doi.org/10.3390/mi12091084

Academic Editors: Cristian Zambelli and Rino Micheloni

Received: 4 August 2021

Accepted: 1 September 2021

Published: 8 September 2021

Publisher's Note: MDPI stays neutral with regard to jurisdictional claims in published maps and institutional affiliations.

Copyright: (c) 2021 by the authors. Licensee MDPI, Basel, Switzerland. This article is an open access article distributed under the terms and conditions of the Creative Commons Attribution (CC BY) license (https:// creativecommons.org/licenses/by/ $4.0 /)$.
IMEC, Kapeldreef 75, B-3001 Leuven, Belgium

* Correspondence: siva.ramesh@imec.be

\begin{abstract}
We studied the metal gate work function of different metal electrode and high-k dielectric combinations by monitoring the flat band voltage shift with dielectric thicknesses using capacitancevoltage measurements. We investigated the impact of different thermal treatments on the work function and linked any shift in the work function, leading to an effective work function, to the dipole formation at the metal/high- $\mathrm{k}$ and/or high- $\mathrm{k} / \mathrm{SiO}_{2}$ interface. We corroborated the findings with the erase performance of metal/high-k/ONO/Si (MHONOS) capacitors that are identical to the gate stack in three-dimensional (3D) NAND flash. We demonstrate that though the work function extraction is convoluted by the dipole formation, the erase performance is not significantly affected by it.
\end{abstract}

Keywords: work function; effective work function; dipole; metal gate; high-k; $\mathrm{SiO}_{2}$; interfacial reaction; MHONOS; erase performance; 3D NAND flash memory

\section{Introduction}

When it comes to low-cost and large density non-volatile memory, three-dimensional (3D) NAND flash memory technology is the industry standard [1,2]. The memory stack used in 3D NAND is inspired by a typical SONOS memory cell, which allows easy vertical integration and is addressed by horizontal word lines (WL). To improve the bit density, the number of cells in the vertical 3D NAND string is increased. This requires the stacking of many WLs, which need to be as thin as possible to limit the total height and mechanical stress of the structure [3]. Tungsten (W) metal-based WL is currently being used by the industry. However, novel materials with lower resistivity are being considered as future candidates to reduce the high resistive-capacitive $(\mathrm{RC})$ delay that results as a consequence of WL thinning and continued stacking of the WLs (i.e., downscaling the metal thickness) in the vertical direction.

Moreover, the WL metal can act as an enabler to improve the 3D NAND erase operation. It was shown that high work function metals, such as $\mathrm{TiN}$ and $\mathrm{Ru}$, can delay the electron injection from the gate (i.e., electrons tunneling from the gate into the charge-trap layer), thereby improving the erase window [4]. It has also been demonstrated [5] that when a metal gate is used in combination with a thin high-k liner, such as $\mathrm{Al}_{2} \mathrm{O}_{3}, \mathrm{HfO}_{2}$, or $\mathrm{ZrO}_{2}$ (i.e., a Metal/High-k/ONO/Si (MHONOS) structure), the erase performance can be further improved. Figure 1 plots the erase saturation levels (lowest possible threshold voltage, $V_{\mathrm{TH}}$, shift achievable) for different scenarios, with and without a high-k liner, as simulated using our in-house developed 1D simulator [6]. The high-k liner helps to lower the injecting field for the electrons at the gate, and even proves to have a larger impact than the metal work function (WF). The erase is found to be penalized when the MHONOS stack is treated with a high thermal budget [3]. To thoroughly investigate the WL metal and high-k liner combination, and its effect on erase operation, metal work function extraction experiments have been proposed and studied in this work. 


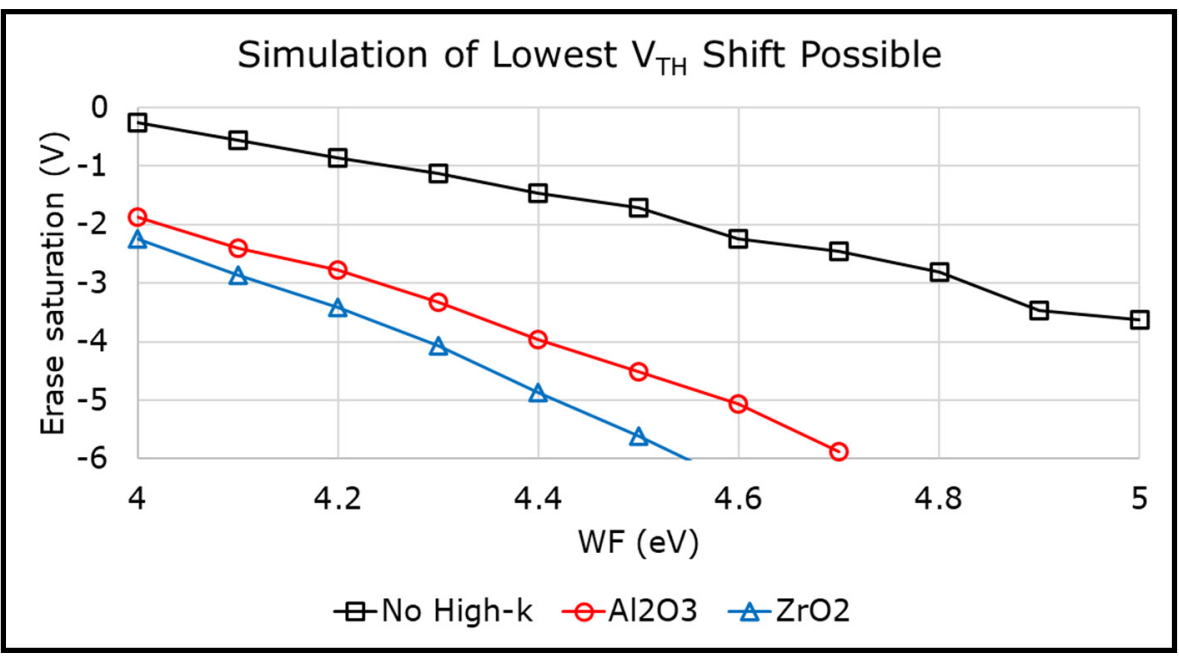

Figure 1. Simulations of erase saturation levels in a memory stack without high-k liner, or with $2 \mathrm{~nm}$ $\mathrm{Al}_{2} \mathrm{O}_{3}$ or $\mathrm{ZrO}_{2}$. Addition of a high-k liner shows more benefit than (work function) WF.

WF analysis of metal gate electrodes on high-k dielectrics, by monitoring flat-band voltage, $V_{F B}$ (or threshold voltage, $V_{T H}$ ), have been demonstrated in the literature [7-12]. The studies report an undesirable shift in the $V_{F B}\left(\right.$ or $V_{T H}$ ) of metal-oxide-semiconductor (MOS) devices. The origins are unclear, leading to an effective work function (eWF) for the metal, different from the bulk values. Some reports in the literature attribute this shift to Fermi level pinning (FLP) caused either by metal-induced gap states [13-15] or charged defects/oxygen transfers, at the metal/high-k interface [12,16,17]. Dipole formation at the high- $\mathrm{k} / \mathrm{SiO}_{2}$ interface due to oxygen vacancies [18,19], and/or the energy offsets between the high- $\mathrm{k}$ and $\mathrm{SiO}_{2}$ [20], have also been suggested in the literature as possible root causes for an eWF. Though, these studies suggest a notable dependence of eWF on the choice of high-k used, other process parameters such as gate electrode deposition and annealing conditions have been found to affect the eWF in a significant way as well [21].

In this paper, we investigate the change in WF (i.e., eWF) of metal electrodes deposited on high-k dielectrics. Based on the process conditions used, we evidence it to either the interfacial reactions at the WL-to-high- $k$ contact or between the high-k and the oxide. The aim of this work is to understand the origins and consequences of WF shifts based on process conditions within the context of 3D NAND flash memory devices. Therefore, we also analyze various MHONOS stacks containing $\mathrm{Al}_{2} \mathrm{O}_{3}, \mathrm{ZrO}_{2}, \mathrm{HfO}_{2}$ high-k liners and TiN, $\mathrm{Ru}, \mathrm{Mo}$ as gate metal, and corroborate the eWF with the erase performance of these stacks.

\section{Materials and Methods}

Capacitors with and without the charge trap layer were fabricated on $300 \mathrm{~mm}$ p-doped $\mathrm{Si}$ (100) wafers for erase analysis and WF extraction, respectively.

\subsection{Work Function Extraction Methodology}

The WF of a metal on high-k is determined by extracting $V_{F B}$ from capacitance-voltage (CV) measurements on a metal-insulator-semiconductor (MIS) structure [22]. The schematic in Figure 2 shows the energy band diagram of an MIS structure. From this, we note that the metal work function can be expressed as follows

$$
\Phi_{M}=V_{F B}+\chi_{S i}+\left[E_{C}-E_{F}\right],
$$

where $\Phi_{M}$ is metal work function, $V_{F B}$ is flat-band voltage computed from CV measurements, $\chi_{S i}$ is electron affinity of $\operatorname{Si}$ substrate, $E_{C}$ and $E_{F}$ are the conduction band minima and fermi level. 


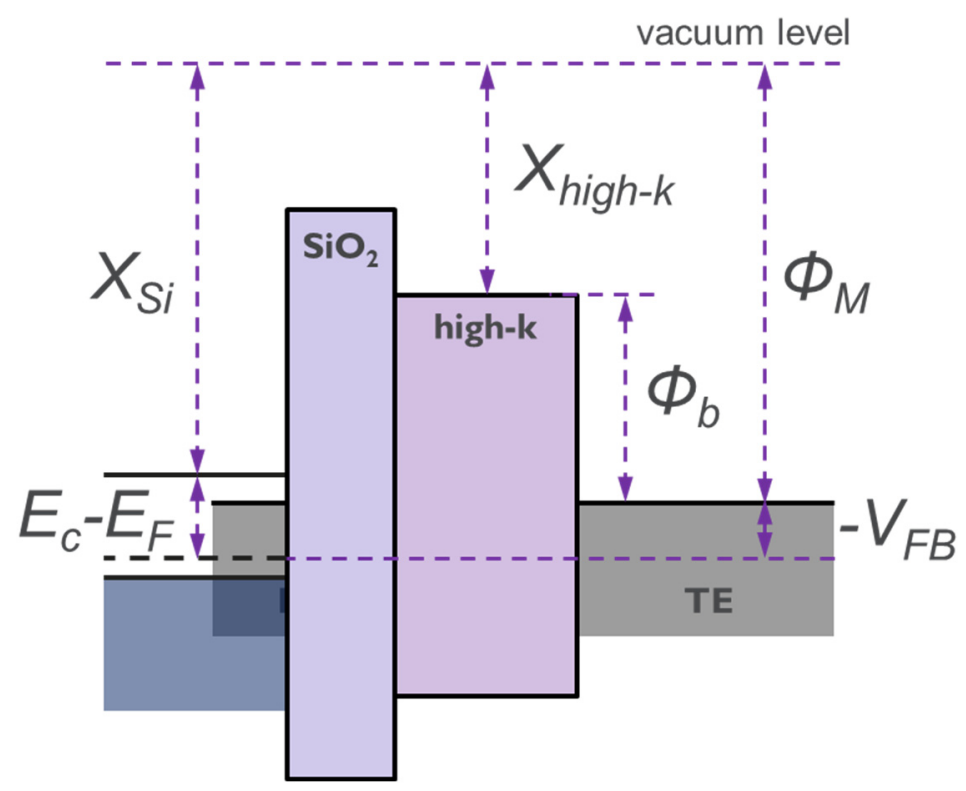

Figure 2. Schematic of the energy band diagram of a metal-insulator-semiconductor (MIS) capacitor.

However, the charges present in the bulk and at the interfaces of the oxides [23] can affect the $V_{F B}$ as follows

$$
\Delta V_{F B}=\int_{0}^{t_{o x}} \frac{\rho(z)\left(t_{o x}-z\right)}{\varepsilon(z) \varepsilon_{0}} d z,
$$

From the above equation, it is clear that the effect of these oxide charges can be cancelled out by extracting the $V_{F B}$ at zero oxide thickness. This calls for variations in $\mathrm{SiO}_{2}$ and high-k thicknesses. With the help of a slant etch technique, the thickness of $\mathrm{SiO}_{2}$ was varied across the wafer as shown in schematic in Figure 3. For each electrode, a set of 3 wafers with different high-k thicknesses (typically $3 \mathrm{~nm}, 5 \mathrm{~nm}, 7 \mathrm{~nm}$ ) was used to provide enough variation and extract the WF conveniently. Typical CV measurements and $V_{F B}$ extraction procedure are discussed in Appendix A.

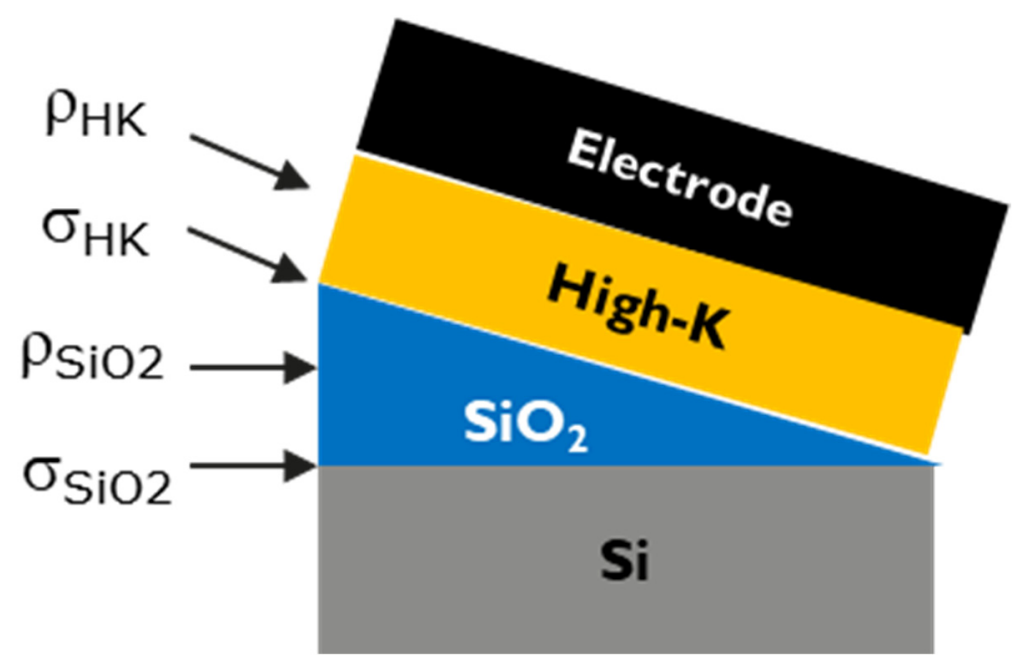

Figure 3. Schematic of MIS capacitor with slant etch for $\mathrm{SiO}_{2}$. Corresponding oxide charge densities are indicated.

The impact of oxide charges on $V_{F B}$ can be mathematically expressed in terms of equivalent oxide thickness (EOT) and the corresponding charge densities as follows [24]

$$
V_{F B}=\Phi_{M S}+q \cdot \rho_{H K} \cdot \varepsilon_{H K} \cdot \frac{E O T_{H K}^{2}}{2 \cdot \varepsilon_{o x}^{2} \cdot \varepsilon_{o}}+q \cdot \sigma_{H K} \cdot \frac{E O T_{H K}}{\varepsilon_{o x} \cdot \varepsilon_{o}}+q \cdot \rho_{S_{i O}} \cdot \frac{0.5 \cdot T_{S_{i O}}^{2}+\left(\frac{\varepsilon_{H K}}{\varepsilon_{o x}}\right) \cdot T_{S_{i O}} \cdot E O T_{H K}}{\varepsilon_{o x} \cdot \varepsilon_{o}}+q \cdot \sigma_{S i O_{2}} \cdot \frac{E O T_{t o t a l}}{\varepsilon_{o x} \cdot \varepsilon_{o}},
$$


where $q$ is the electron charge, $\rho_{H K}$ and $\sigma_{H K}$ are the bulk and interface charge densities of high-k dielectric, respectively. The terms $\rho_{\mathrm{SIO} 2}$ and $\sigma_{\mathrm{SIO} 2}$ are the corresponding bulk and interface charge densities of $\mathrm{SiO}_{2}$, respectively. EOT $\mathrm{HK}_{\mathrm{K}}, T_{\mathrm{SiO} 2}$, and $E O T_{\text {total }}$ are the equivalent oxide thickness of high-k, thickness of $\mathrm{SiO}_{2}$, and both combined, respectively. The EOT total is in fact the measured EOT computed from the $\mathrm{CV}$ measurement of the MIS capacitors. The terms $\varepsilon_{H K}, \varepsilon_{o x}, \varepsilon_{0}$ are the relative permittivity of high-k, $\mathrm{SiO}_{2}$ and permittivity of free space, respectively. The $\Phi_{M S}$ in the above equation, from which the metal WF is extracted, is later computed by extrapolating $V_{F B}$ at EOT (both high-k and $\left.\mathrm{SiO}_{2}\right)=0$.

First, a $30 \mathrm{~nm}$ thick layer of high quality $\mathrm{SiO}_{2}$ was thermally grown at $900{ }^{\circ} \mathrm{C}$. This was then etched back with a slant profile (as shown in Figure 3) by slowly immersing (at a constant rate) the wafer in a $1.9 \%$ hydrofluoric acid (HF) solution. The desired thickness range of $\mathrm{SiO}_{2}$ is obtained across the wafer by modifying the rate of immersion accordingly. A nominal thickness range of 3-12 nm was used in this work. Then, after the slant etch, a $3 \mathrm{~nm}$ plasma enhanced atomic layer deposition (PEALD) $\mathrm{SiO}_{2}$ was uniformly deposited at $300{ }^{\circ} \mathrm{C}$, to mimic the blocking oxide in a 3D NAND device. Little wafer-to-wafer variations were observed in the oxide thickness, as measured by ellipsometry (see Figure 4a). The total EOT measured from CV will vary across the wafer due to the slant etch of thermal oxide, as shown in Figure 4b (bubble size represents magnitude of EOT).

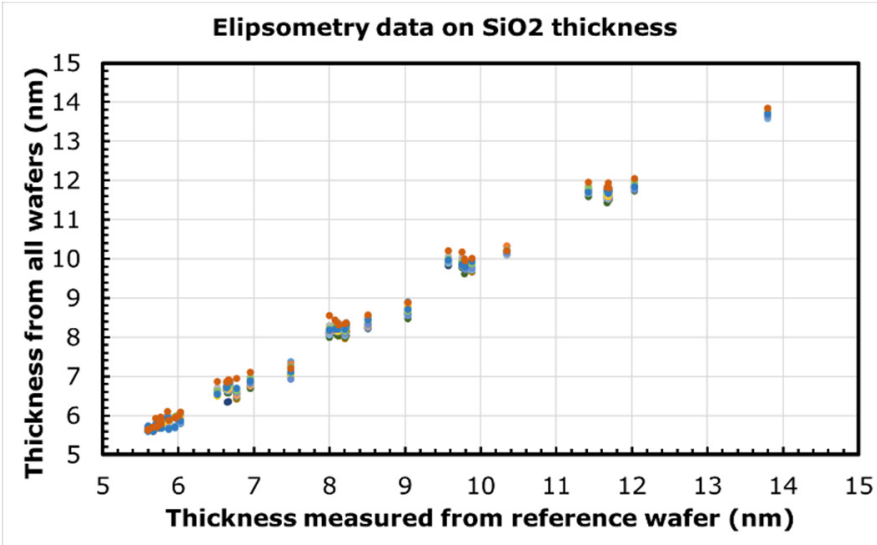

(a)

\section{EOT}

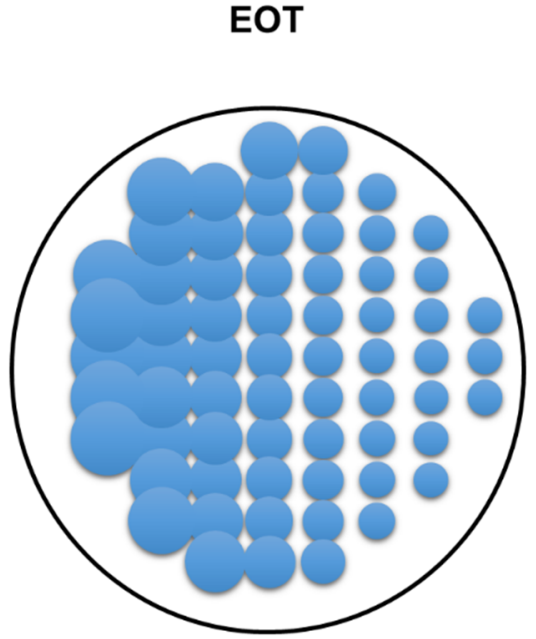

(b)

Figure 4. (a) Thickness of $\mathrm{SiO}_{2}$, after slant etch and plasma enhanced atomic layer deposition (PEALD) oxide deposition, measured across multiple wafers using ellipsometry; (b) Equivalent oxide thickness (EOT) computed from capacitancevoltage (CV) measurement. Bubble size represents EOT magnitude.

After this, high-k liners, such as $\mathrm{Al}_{2} \mathrm{O}_{3}, \mathrm{ZrO}_{2}$, and $\mathrm{HfO}_{2}$, were deposited at $300{ }^{\circ} \mathrm{C}$ to their desired thicknesses, using atomic layer deposition (ALD). Finally, $20 \mathrm{~nm}$ ALD Ru or ALD TiN or PVD Mo were then deposited as the gate electrode. In order to isolate the impact of thermal treatment on individual layers, a high temperature anneal $\left(T_{\text {anneal }}\right)$ was performed at different stages of the stack formation (as shown in Figure 5). For instance, some of the capacitors were subjected to a post metallization anneal (PMA) for $20 \mathrm{~min}$ at $750{ }^{\circ} \mathrm{C}$ in $\mathrm{N}_{2}$ ambient. A few others were subjected to a post high-k deposition anneal (PDA), where the entire stack sans the metal electrode received a thermal treatment for $1 \mathrm{~min}$ at $1050{ }^{\circ} \mathrm{C}$ for $\mathrm{Al}_{2} \mathrm{O}_{3}$-based stacks and $1 \mathrm{~min}$ at $750{ }^{\circ} \mathrm{C}$ for the rest, all in $\mathrm{N}_{2}$ ambient. All wafers received a final sintering anneal in $5 \mathrm{~atm} \mathrm{H}_{2}$ ambient at $450^{\circ} \mathrm{C}$ for $30 \mathrm{~min}$. 


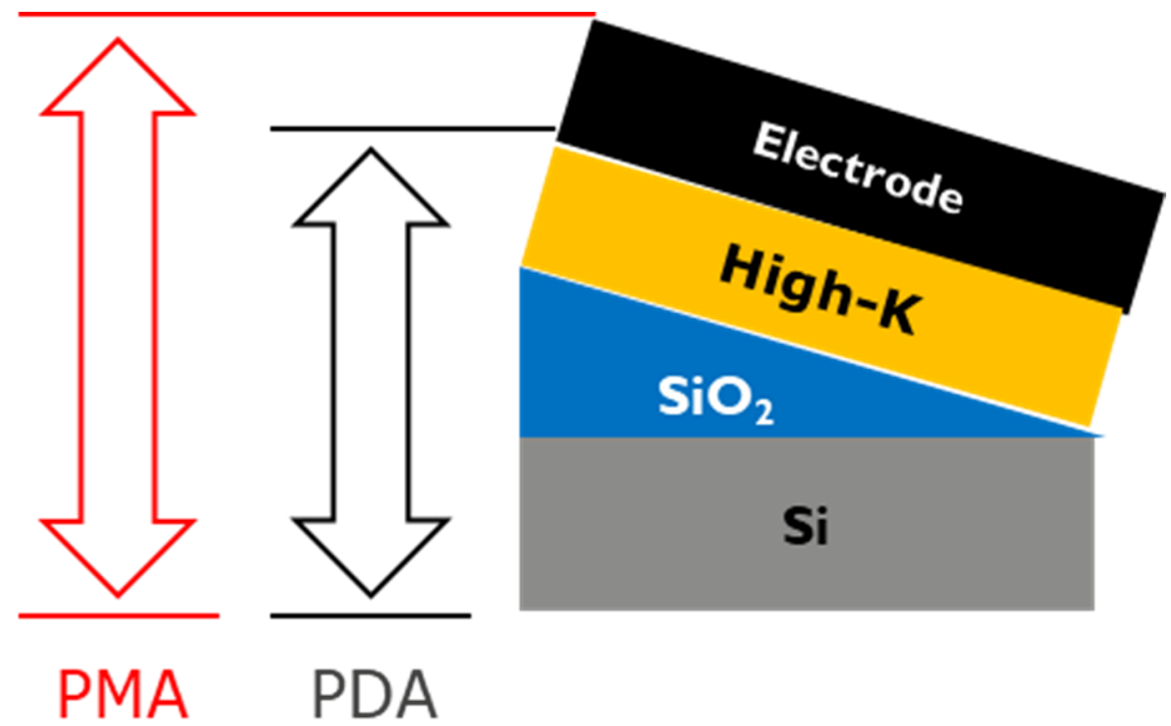

Figure 5. Schematic indicating different anneal types and the corresponding layers that received the process.

$\mathrm{CV}$ measurements were performed on $70 \times 70 \mu \mathrm{m}^{2}$ capacitors at a frequency of $100 \mathrm{kHz}$. The parameters needed for the WF extraction, namely, $V_{F B}$, the substrate doping concentration and the total EOT, $\mathrm{EOT}_{\text {total, }}$ are estimated (see Appendix A) with the help of NCSU's CVC model fitting software [25]. Based on the expression for $V_{F B}$ from Equation (3), we can express $V_{F B}$ as a second order polynomial equation in terms of the EOT, as the one below

$$
V_{F B}=\Phi_{M S}+a \cdot E O T_{H K}^{2}+b \cdot E O T_{H K}+p \cdot T_{S_{i O}}^{2}+q \cdot T_{S i O_{2}}
$$

where $a, b, p$, and $q$ contain the charge densities of high- $\mathrm{k}$ and $\mathrm{SiO}_{2}$.

From the above equation, we can first eliminate the effect of charges in $\mathrm{SiO}_{2}$ with a second order polynomial fit of the $V_{F B}$ with the thickness of $\mathrm{SiO}_{2}, T_{S i O 2}$. A sample fit is shown in Figure 6. The intercept from the first fit contains the polynomial equation with high-k EOT, EOT $_{\mathrm{HK}}$ and hence is used to eliminate the charges from high-k in a second fit.

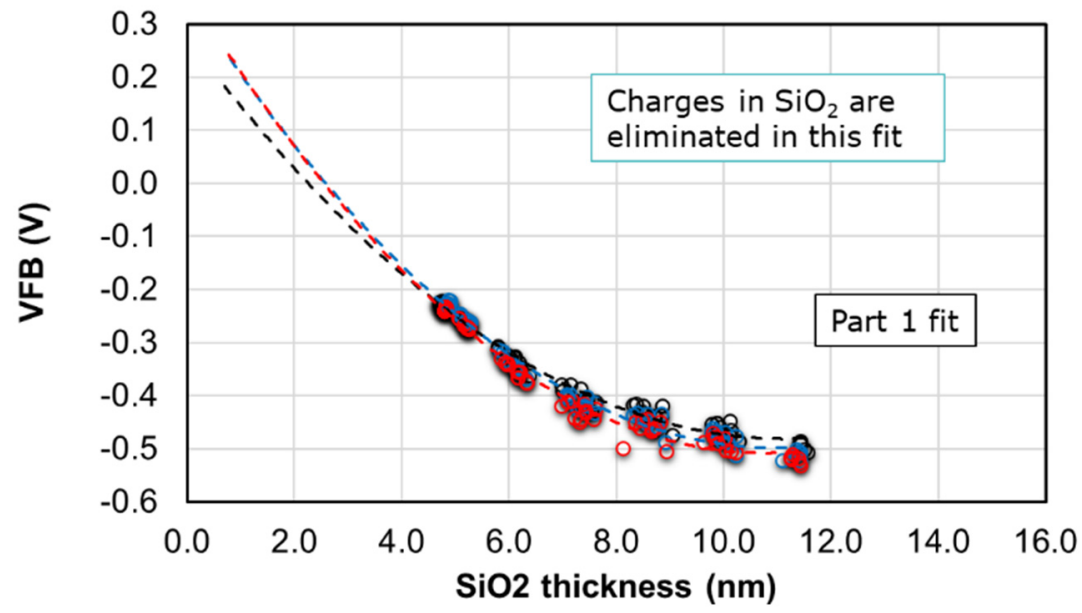

Figure 6. The $V_{F B}$ measured from $\mathrm{CV}$ is plotted as a function of $\mathrm{SiO}_{2}$ thickness. A second order fit is performed to isolate the terms $\mathrm{p}$ and $\mathrm{q}$ containing the charge densities in its bulk and interface.

As mentioned earlier, we have the $E O T_{\text {total }}$ of the stack as measured from $\mathrm{CV}$. In order to get the $T_{\mathrm{SiO} 2}$ to be used in the first fit, we make use of the ellipsometry data that was measured at preset locations across the wafer, after the slant etch and PEALD deposition. This data is then compared with corresponding dies for which the CV was measured. The 
difference between the measured $E O T_{\text {total }}$ and this ellipsometry data will give an estimate of the $E O T_{H K}$.

The three curves shown in Figure 6 represent the three wafers with three different high-k thicknesses needed for sufficient variation to eliminate the charges affecting the $V_{F B}$. The corresponding intercept from the 2nd order fit of the above curves is then used in a second fit, as shown in Figure 7 below.

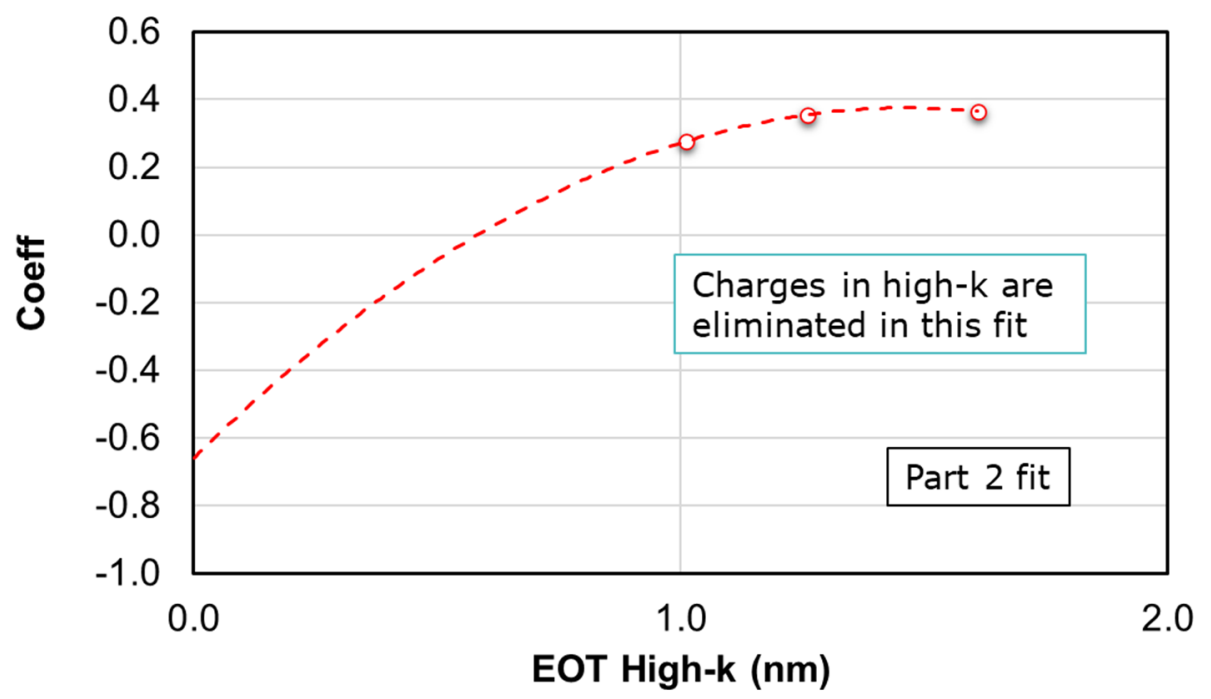

Figure 7. The intercepts from the part 1 fit are plotted as a function of high-k EOT. A second order fit is performed to extract the metal work function.

The intercepts vs. the $\mathrm{EOT}_{\mathrm{HK}}$ will now help to eliminate the charges in high-k. The intercept from this second fit is the $\Phi_{M S}$ from which the WF is computed using the formula

$$
W F=4.05+\Phi_{M S}+E_{C}-E_{F}
$$

where $E_{C}-E_{F}($ in eV $)=1.12-0.0257 * \ln \left(\frac{1.83 E 19}{\text { median doping concentration in the substrate }}\right)$.

\subsection{NAND Flash Erase Analysis}

Incremental Step Pulse Erase (ISPE) characteristics were studied by monitoring the shift in $V_{T H}$ of MHONOS capacitors from their fresh state. The erase operation is divided into a number of steps with increasing amplitude (for a duration of $1 \mathrm{~ms}$ ) in applied voltage and at the end of each of them a verify operation is applied to check the $V_{T H}$. The amplitude and rate of change in $V_{T H}$ is considered as a measure of erase performance.

Large MHONOS capacitors $\left(50 \times 50 \mu \mathrm{m}^{2}\right)$ were fabricated on $300 \mathrm{~mm}$ p-doped Si (100) wafers, as shown in Figure 8b. $\mathrm{N}^{+}$-doped rings were processed, surrounding the active area of the capacitors, to provide minority carriers for program operation. In a study reported elsewhere [3], we have demonstrated a 3D NAND test structure with 5 layers and showed that the memory characteristics of the stack (see Figure 8a) are qualitatively similar to that of the planar test structures that we typically use (see Figure $8 \mathrm{~b}$ ). Moreover, the gate stack deposited in this work mimics the one of 3D NAND in production $[3,26]$ in terms of annealing processes and high- $\mathrm{k} /$ metal gate depositions performed. Therefore, we could fairly say that the results obtained from the planar capacitors in this work are relevant for 3D NAND flash memory devices. 


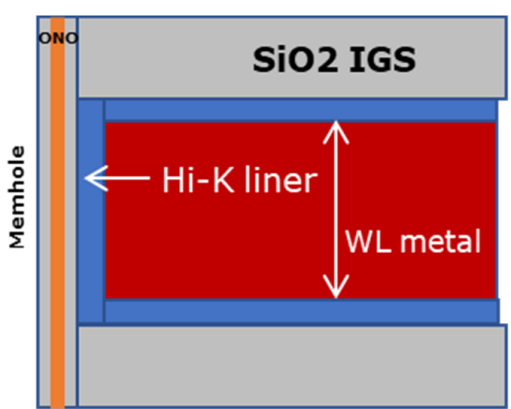

(a)

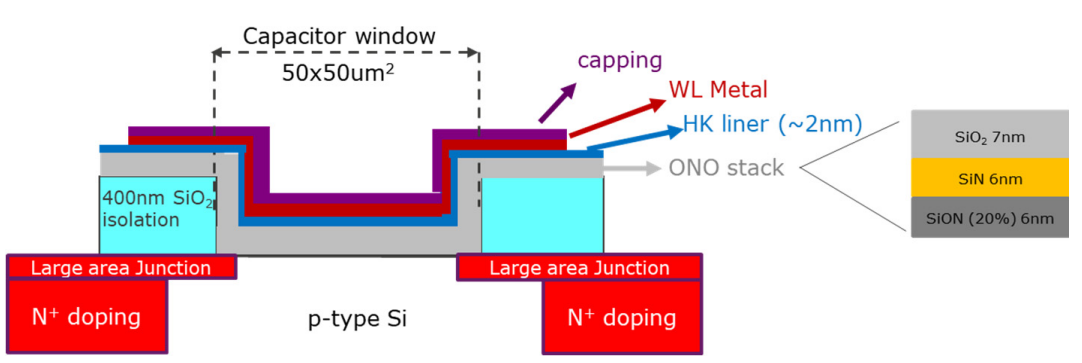

(b)

Figure 8. (a) Cross-section schematic of the memory gate stack in a vertical three-dimensional (3D) NAND device; (b) schematic of a planar test structure used in this work. The components of the gate stack are indicated in the figure.

The MHONO stack, as seen from the TEM image in Figure 9a, consists of a $6 \mathrm{~nm}$ $\mathrm{SiON}$ (with 20\% N-to-O ratio) tunnel layer deposited using CVD at $780{ }^{\circ} \mathrm{C}, 6 \mathrm{~nm} \mathrm{LPCVD}$ $\mathrm{Si}_{3} \mathrm{~N}_{4}$ charge trap layer deposited at $690^{\circ} \mathrm{C}, 7 \mathrm{~nm} \mathrm{PEALD} \mathrm{SiO}_{2}$ blocking oxide deposited at $300{ }^{\circ} \mathrm{C}$, and $2 \mathrm{~nm} \mathrm{ALD} \mathrm{Al}_{2} \mathrm{O}_{3}$ or $\mathrm{ZrO}_{2}$ or $\mathrm{HfO}_{2}$ high-k liner deposited at $300{ }^{\circ} \mathrm{C}$. A total of $20 \mathrm{~nm}$ ALD Ru or ALD TiN or PVD Mo were then deposited as the gate electrode (WL, wordline). Similar to the study of WF extraction, a post metallization anneal, PMA for $20 \mathrm{~min}$ at $750{ }^{\circ} \mathrm{C}$ in $\mathrm{N}_{2}$ ambient, and a post deposition anneal, PDA for $2 \mathrm{~min}$ at $1050{ }^{\circ} \mathrm{C}$ for $\mathrm{Al}_{2} \mathrm{O}_{3}$ based stacks and $1 \mathrm{~min}$ at $750{ }^{\circ} \mathrm{C}$ for the rest, all in $\mathrm{N}_{2}$ ambient, were performed for some of the capacitors (see Figure $9 \mathrm{~b}$ ). All wafers were subject to a final sintering anneal either in forming gas at $420{ }^{\circ} \mathrm{C}$ for $20 \mathrm{~min}$ or in $5 \mathrm{~atm} \mathrm{H}_{2}$ ambient at $450{ }^{\circ} \mathrm{C}$ for $30 \mathrm{~min}$. We may note that the sintering anneal has little influence on the final erase saturation levels.

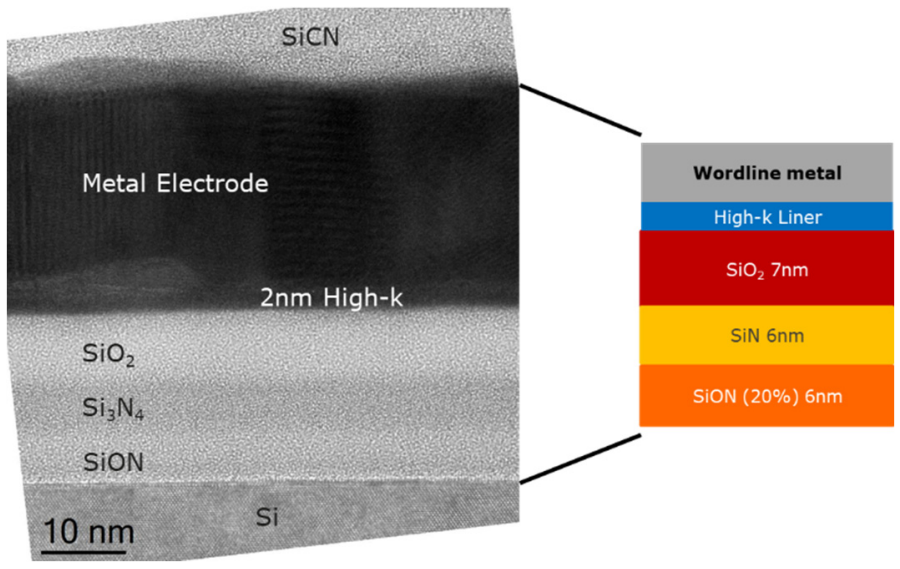

(a)

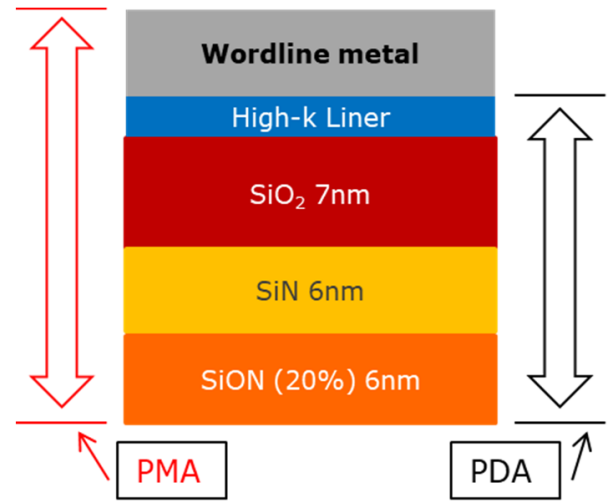

(b)

Figure 9. (a) Transmission electron microscope (TEM) image of a memory stack fabricated in this work; (b) different anneal types and the corresponding MHONOS layers that received the anneal.

\section{Results and Discussion}

The metal WF extracted in this work are listed as a histogram plot in Figure 10 for a few metal/high-k combinations. No high temperature anneals were performed for these splits. W Ref represents the CVD W/thin $(3 \mathrm{~nm}) \mathrm{ALD} \mathrm{TiN} / \mathrm{Al}_{2} \mathrm{O}_{3}$ liner stack similar to the one used currently in 3D NAND production. We could note that the WF of TiN in combination with $\mathrm{Al}_{2} \mathrm{O}_{3}$ is estimated to be about $4.53 \mathrm{eV}$ and is in close agreement with the actual TiN WF reported in the literature $[27,28]$. What is surprising is the WF of $\mathrm{Ru}$ in combination with $\mathrm{Al}_{2} \mathrm{O}_{3}$, which is about 200-300 meV less than those reported in the literature for $\mathrm{Ru}$ metal $[29,30]$. It has been demonstrated, using internal photoemission experiments [31], that subtle changes in the chemical bonding at the metal/high-k interface can cause 
a significant impact on the barrier height $\left(\Phi_{b}\right.$, as shown in Figure 2$)$ at this interface. Such chemical modifications could occur from various processing, such as conditions of deposition, thermal budget, and ambient of annealing process. As a consequence, this could lead to a shift in the WF of the metal. However, it is possible to avert this interfacial reaction by using appropriate interfacial layer (IL), as can be seen from Figure 10. The WF of $\mathrm{Ru}$ improves to $4.8 \mathrm{eV}$ by adding a thin $\left(3 \mathrm{~nm}\right.$ ) TiN liner between $\mathrm{Ru}$ and $\mathrm{Al}_{2} \mathrm{O}_{3}$.

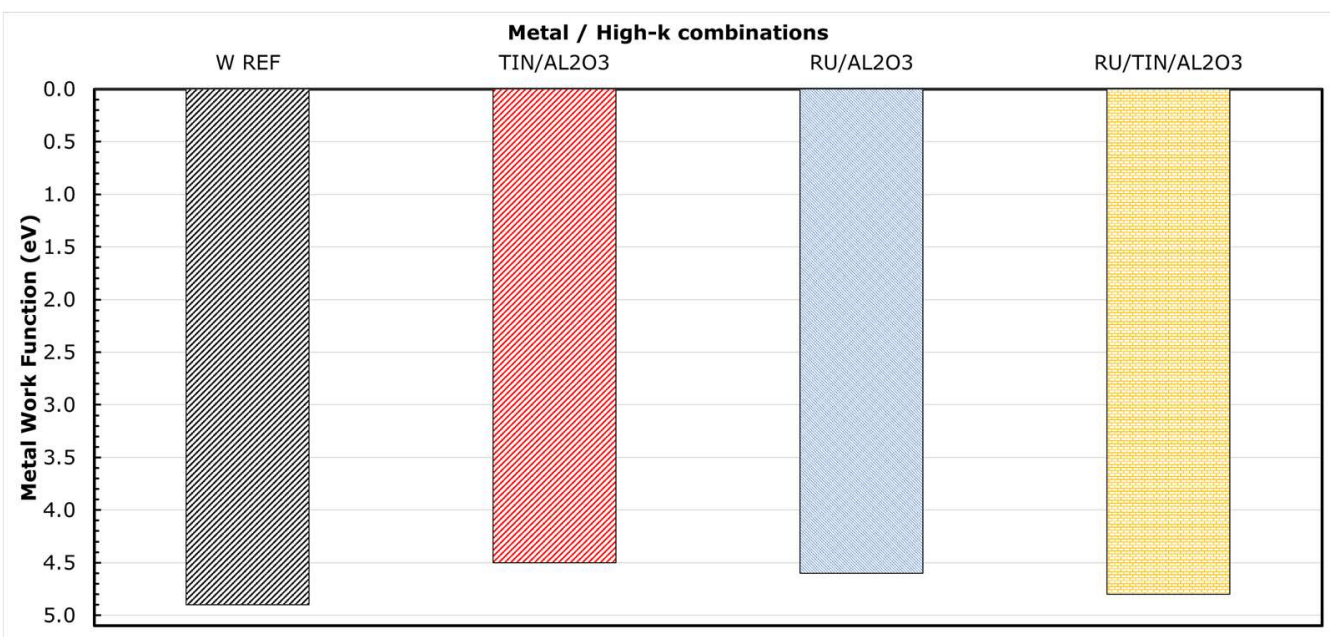

Figure 10. Metal work function listed for a few metal/high-k combinations from this work. No high temperature anneals were performed for these stacks.

In order to verify whether these shifts, measured in WF of Ru, reflect the actual change in metal WF, we compared the erase performance of these stacks. Figure 11 shows the ISPE curves for MHONOS stacks containing the metal/high-k combinations from Figure 10. The erase saturation (lowest VT shift achieved in ISPE) for TiN and $\mathrm{Ru}$ on $\mathrm{Al}_{2} \mathrm{O}_{3}$ (WF $\sim 4.6 \mathrm{eV}$ ) is comparable after accounting for the differences in the starting $V_{T H}$, while that of $\mathrm{W}$ Ref (WF $\sim 4.9 \mathrm{eV}$ ) is better, corroborating the WF difference between these stacks. With the addition of TiN liner, the WF of Ru improves, and so does the erase saturation.

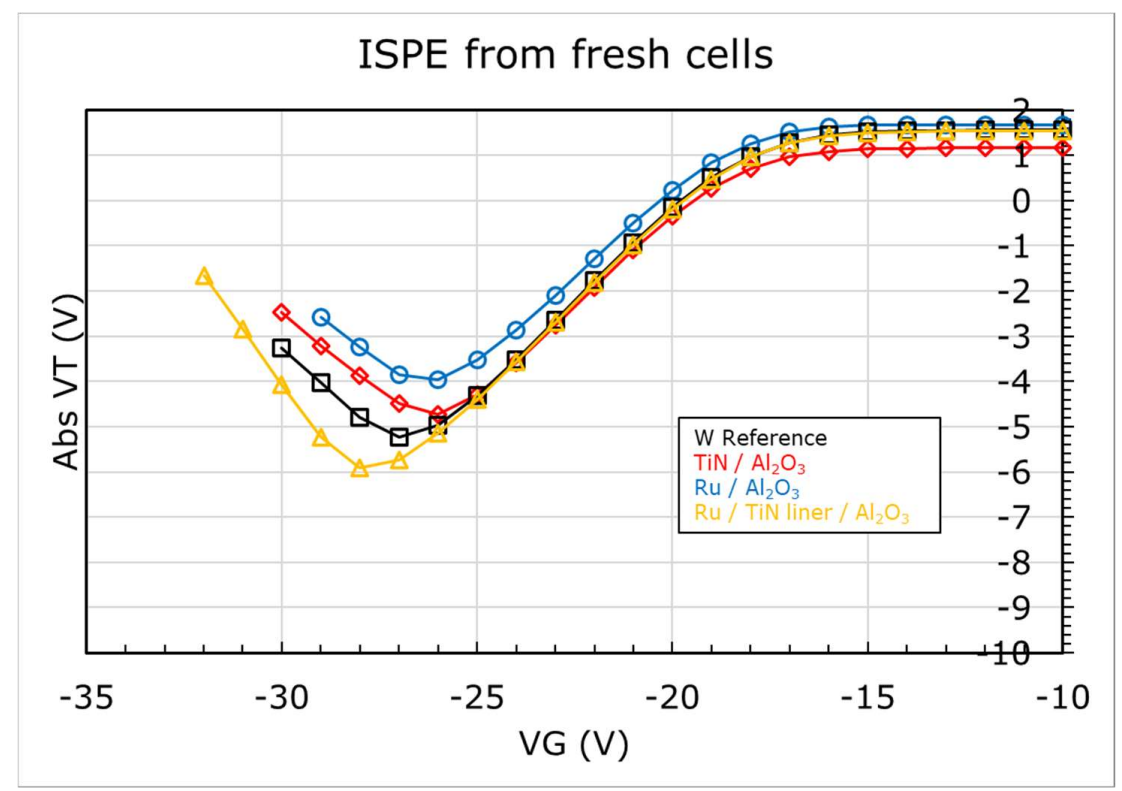

Figure 11. Incremental Step Pulse Erase (ISPE) of (Metal/High-k/ONO/Si) MHONOS, for different metal/high-k combinations from Figure 10. 
We may note that the WF extracted from the $\mathrm{Ru} / \mathrm{TiN} / \mathrm{Al}_{2} \mathrm{O}_{3}$ stack is slightly less than that of $\mathrm{W}$ Ref, i.e., $\mathrm{W} / \mathrm{TiN} / \mathrm{Al}_{2} \mathrm{O}_{3}$ stack, yet the erase is better with $\mathrm{Ru}$. Before addressing this, let us look at Figure 12a,b, which display the WF extracted for $\mathrm{Ru}, \mathrm{Mo}$, and TiN in combination with $\mathrm{HfO}_{2}, \mathrm{ZrO}_{2}$, and $\mathrm{Al}_{2} \mathrm{O}_{3}$ after different annealing conditions, as described in Figure 5. From Figure 12a, we could note a significant reduction $(>500 \mathrm{meV})$ in the WF of Ru after the thermal treatment, irrespective of whether the metal electrode received the anneal (PMA) or not (PDA). The ISPE curves for these stacks are shown in Figure 13a. The stack that received the PDA does not change in erase while the one that received a PMA degrades both in erase slope and saturation level. We can also note from Figures $12 \mathrm{~b}$ and $13 \mathrm{~b}$ that without any high temperature anneals, both $\mathrm{Ru}$ and $\mathrm{Mo}$ show similar WF and erase saturation levels in combination with $\mathrm{ZrO}_{2}$. Though after a thermal treatment (PMA or PDA), the WF reduces irrespective of the metal or high-k used, the erase saturation depends on the type of anneal applied. These observations (made from Figure 10, Figure 12, Figure 13) hint that (a) the WF alone is not the reason for erase functionality, and (b) an extra factor, unaccounted in the extraction, is affecting the WF, resulting in an effective work function, eWF, being measured from the experiments.

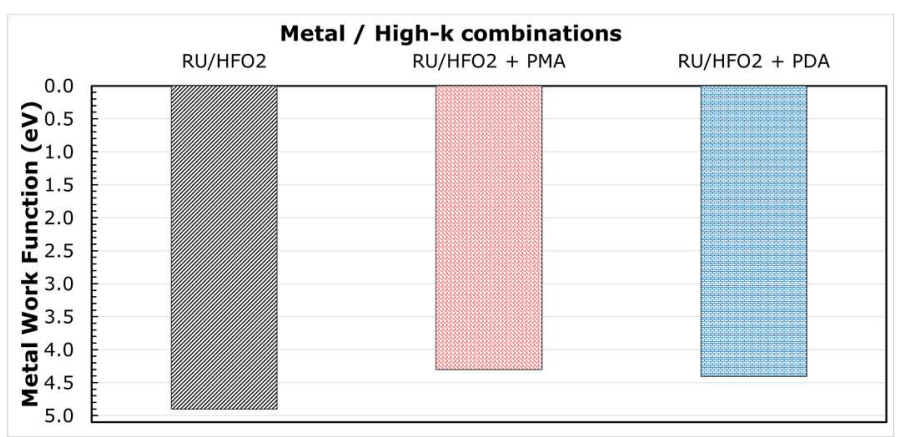

(a)

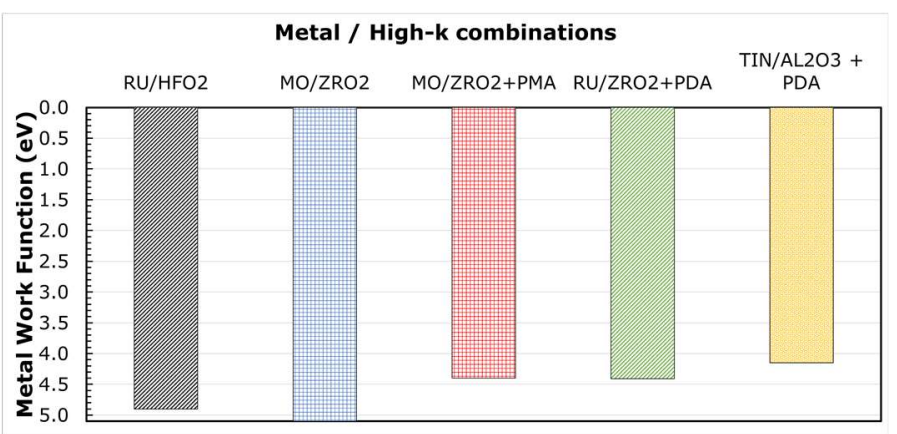

(b)

Figure 12. WF extracted for multiple metal and high-k combinations after different annealing conditions. (a) $\mathrm{Ru}_{\mathrm{with}} \mathrm{HfO}_{2}$; (b) $\mathrm{Ru}$, Mo with $\mathrm{ZrO}_{2}$, and TiN with $\mathrm{Al}_{2} \mathrm{O}_{3}$.

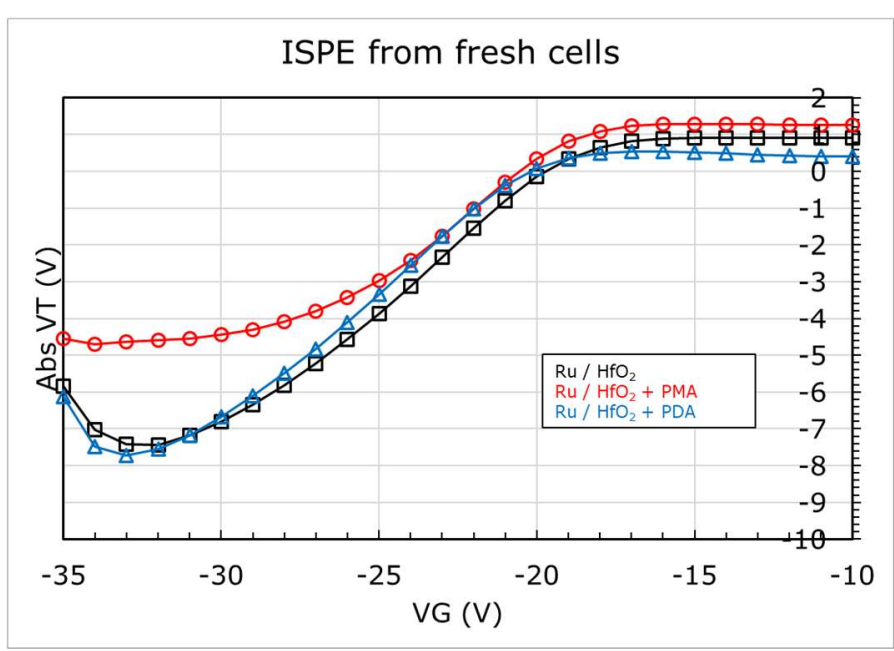

(a)

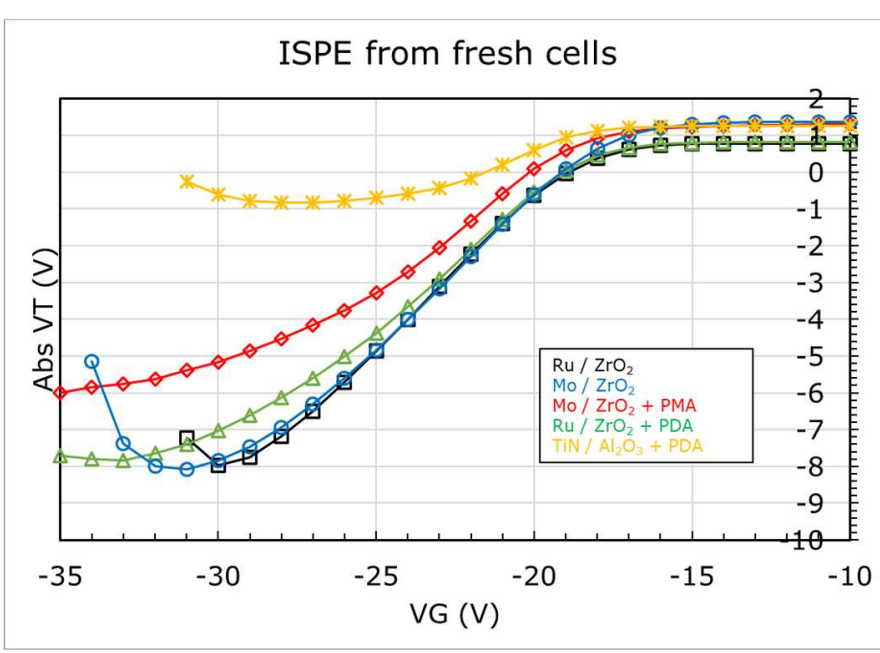

(b)

Figure 13. ISPE of MHONOS stacks for (a) $\mathrm{Ru} / \mathrm{HfO}_{2}$. Erase performance degrades with post metallization anneal (PMA) while no change after a post high-k deposition anneal (PDA); (b) Ru and Mo with $\mathrm{ZrO}_{2}$ and TiN with $\mathrm{Al}_{2} \mathrm{O}_{3}$. Similar degradation after PMA as in the case with $\mathrm{HfO}_{2}$. However, worse performance with $\mathrm{Al}_{2} \mathrm{O}_{3}$.

It is important to note that in the case of TiN with $\mathrm{Al}_{2} \mathrm{O}_{3}$ (PDA performed at $2 \mathrm{~min}$ $1050{ }^{\circ} \mathrm{C}$ ), the degradation in erase saturation is much worse, which is unlike the obser- 
vations made for $\mathrm{HfO}_{2}$ - and $\mathrm{ZrO}_{2}$-based stacks, and definitely not reflected in the WF reduction in TiN. A closer study on the high-k material properties reported elsewhere [32], investigated by trap spectroscopy, revealed that worse erase saturation levels at increased thermal budgets could be due to an increase in defect density in the high-k rather than a reduction in the metal WF itself. Higher defect density could increase trap-assisted tunneling [33], thereby increasing the leakage current during the erase operation (a typical band diagram during erase can be seen in Figure 14).

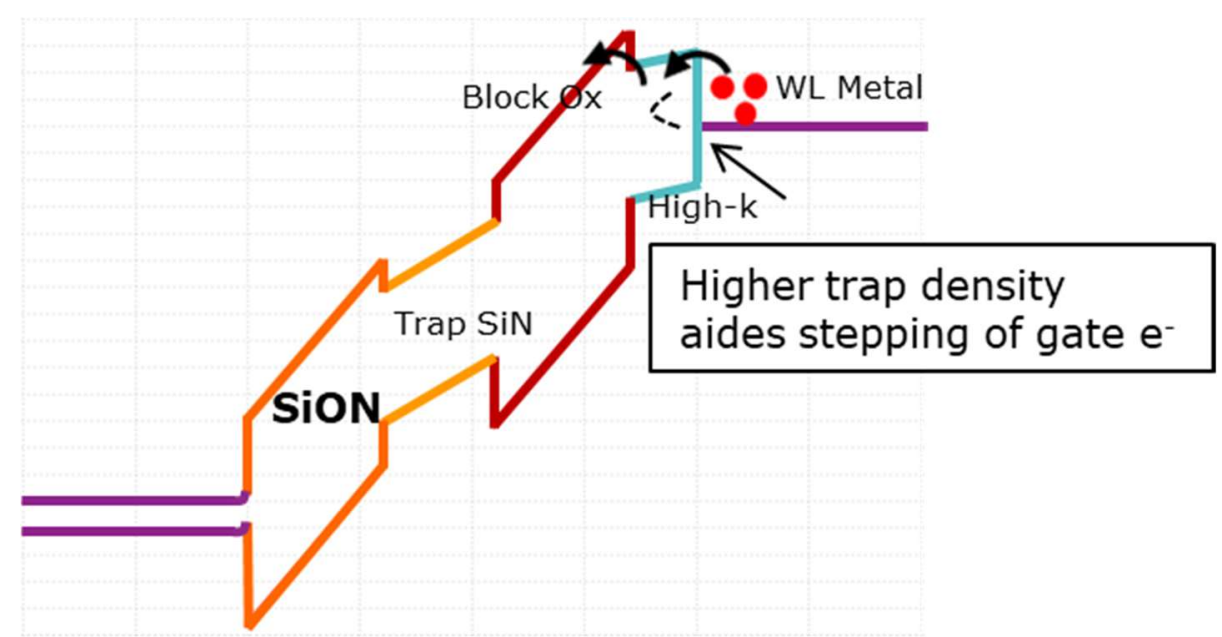

Figure 14. A typical band diagram of MHONOS during erase. Higher trap density reduces the tunneling path for gate electrons resulting in poor erase.

As discussed before, Fermi level pinning (FLP) at the metal/high-k interface, dipole formation at the high- $\mathrm{k} / \mathrm{SiO}_{2}$ interface, and/or the energy offsets between the high- $\mathrm{k}$ and $\mathrm{SiO}_{2}$ have been suggested in the literature as possible root causes for an eWF. If the metal fermi level is pinned, then the $\Phi_{b}$ at the interface should be different, which reflects in the erase saturation levels. Based on the observations made from Figure 11 for Ru with TiN liner and Figure 13 for Ru stacks after PDA, this effect can be ruled out. A common opinion in the literature [21,34-36] is that a dipole formed at the high- $\mathrm{k} / \mathrm{SiO}_{2}$ interface is the dominant factor causing appreciable shifts in $V_{F B}$, and hence, the WF extracted from it. Many physical models exist to explain this dipole formation, attributing it to dielectric contact induced gap states [37] or dictated by the electronegativity and ionic radii of the cations (from the high-k) [38], However, the most acceptable explanation seems to be oxygen vacancies driven by structural stabilization at the high-k/ $\mathrm{SiO}_{2}$ interface $[18-21,34,39,40]$. Moreover, the dipole formation at the high- $\mathrm{k} / \mathrm{SiO}_{2}$ interface should not affect the erase performance of flash memory, which is determined by the electron injection dynamics at the gate contact.

To further clarify the impact of dipole formation on erase performance of flash memory, dipole-forming interlayers (DIL) [36,41,42], namely, $\mathrm{Al}_{2} \mathrm{O}_{3}$ and $\mathrm{La}_{2} \mathrm{O}_{3}(0.6 \mathrm{~nm}$ each), were studied as part of the MHONOS stack (shown in Figure 15). The DIL were deposited between metal and high-k or high-k and $\mathrm{SiO} 2$, with $\mathrm{TiN} / \mathrm{HfO}_{2}$ being used as the control gate electrode and high-k dielectric. All the stacks received a PDA for $1.5 \mathrm{~s}$ at $1050{ }^{\circ} \mathrm{C}$ in $\mathrm{N}_{2}$ ambient. The corresponding shifts in $V_{F B}$ caused by the interlayers were extracted from CV measurements using CVC fitting (as can be seen in Figure 16). 

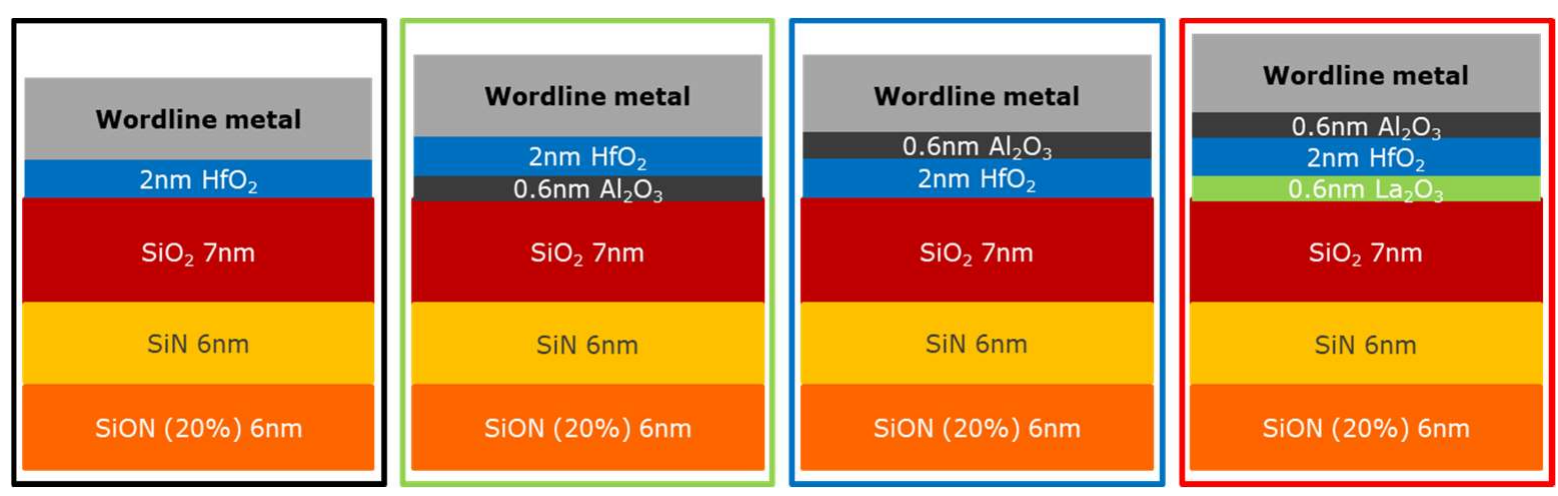

Figure 15. Schematic of MHONOS stacks with dipole-forming interlayers at different locations. $\mathrm{Al}_{2} \mathrm{O}_{3}$ and $\mathrm{La}_{2} \mathrm{O}_{3}$, each $0.6 \mathrm{~nm}$ thin, were used as interlayers with $\mathrm{HfO}_{2}$ used for high-k value.

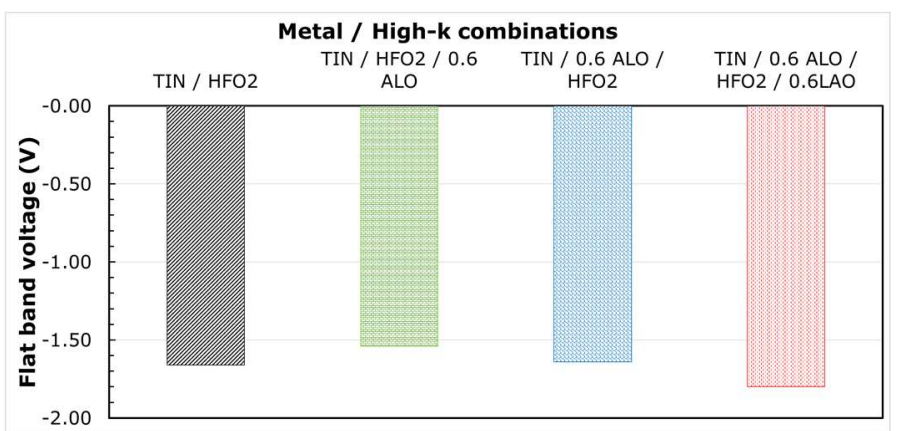

(a)

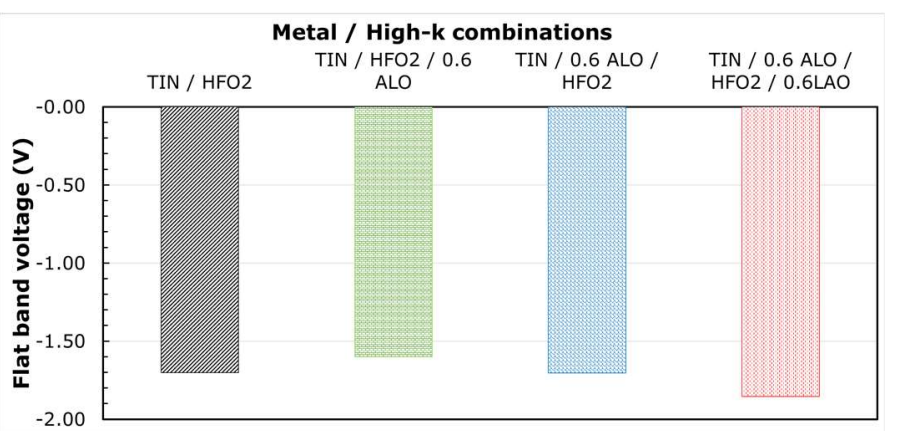

(b)

Figure 16. Flat band voltage monitored from $\mathrm{CV}$ traces, for MHONOS stacks with different dipole interlayers from Figure 15 (a) without any PMA and (b) with PMA for $20 \mathrm{~min}$ at $750{ }^{\circ} \mathrm{C}$ in $\mathrm{N}_{2}$ ambient.

We could note from Figure 16a that with the addition of $\mathrm{Al}_{2} \mathrm{O}_{3}$ DIL between $\mathrm{HfO}_{2}$ and $\mathrm{SiO}_{2}$, the $V_{F B}$ positively increases by about $120 \mathrm{meV}$, while it remains unchanged when $\mathrm{Al}_{2} \mathrm{O}_{3}$ is inserted between the metal and high-k. Though much higher $V_{F B}$ shifts are theoretically reported for $\mathrm{Al}_{2} \mathrm{O}_{3}$ [18], the processing conditions and thickness of the DIL play a major role in determining the magnitude of the $V_{F B}$ shifts $[21,42,43]$. Furthermore, if we add $0.6 \mathrm{~nm} \mathrm{La} 2 \mathrm{O}_{3}$ DIL between $\mathrm{HfO}_{2}$ and $\mathrm{SiO}_{2}$ while keeping the $\mathrm{Al}_{2} \mathrm{O}_{3}$ between TiN and $\mathrm{HfO}_{2}$, we notice a negative drop of about $140 \mathrm{meV}$ in the $V_{F B}$, which is in line with trends reported in the literature [44,45]. It is worth to note that the trend in $V_{F B}$ remains unchanged after a PMA for $20 \mathrm{~min}$ at $750{ }^{\circ} \mathrm{C}$ in $\mathrm{N}_{2}$ ambient (see Figure 16b).

The ISPE curves for these stacks without PMA are shown in Figure 17a. We could note, despite the differences in $V_{F B}$, that there is no difference in the erase performance of these stacks. On the contrary, when the stacks were subjected to PMA, the erase depends on the material present in the stack, as can be seen in Figure 17b. The control sample with only TiN and $\mathrm{HfO}_{2}$ shows slight degradation after PMA. However, the stacks with DIL show higher reduction in erase, even worse when the $\mathrm{Al}_{2} \mathrm{O}_{3}$ is present next to the blocking oxide, though it shows a positive $V_{F B}$ shift (indicating a higher eWF). It is well known that $\mathrm{Al}_{2} \mathrm{O}_{3}$ dielectric suffers from a wider band of defect profile [46]. Recalling the discussion from before on the possible impact of defect density in the high-k on erase (see Figure 14), we could fairly say that the above results corroborate this hypothesis. 


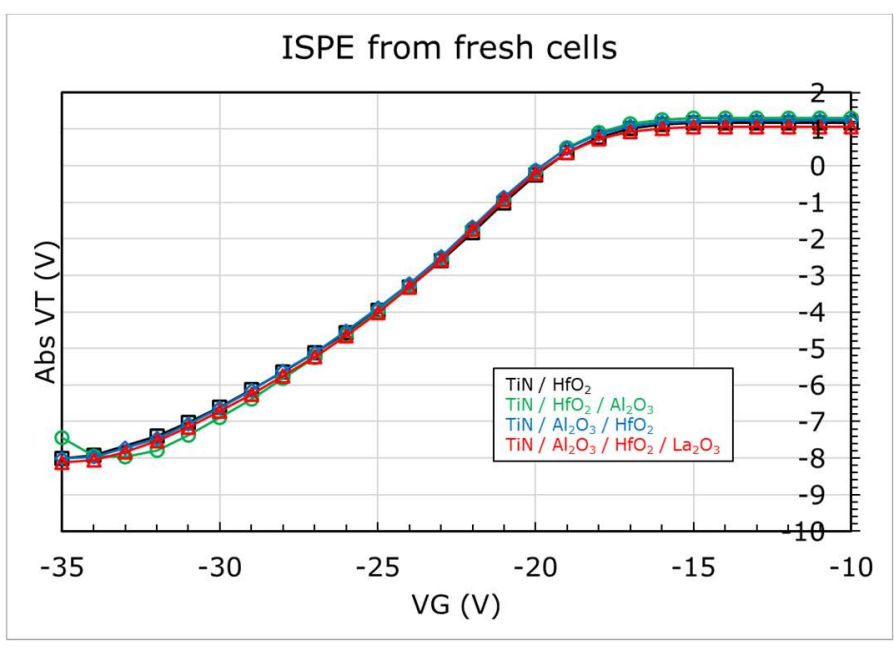

(a)

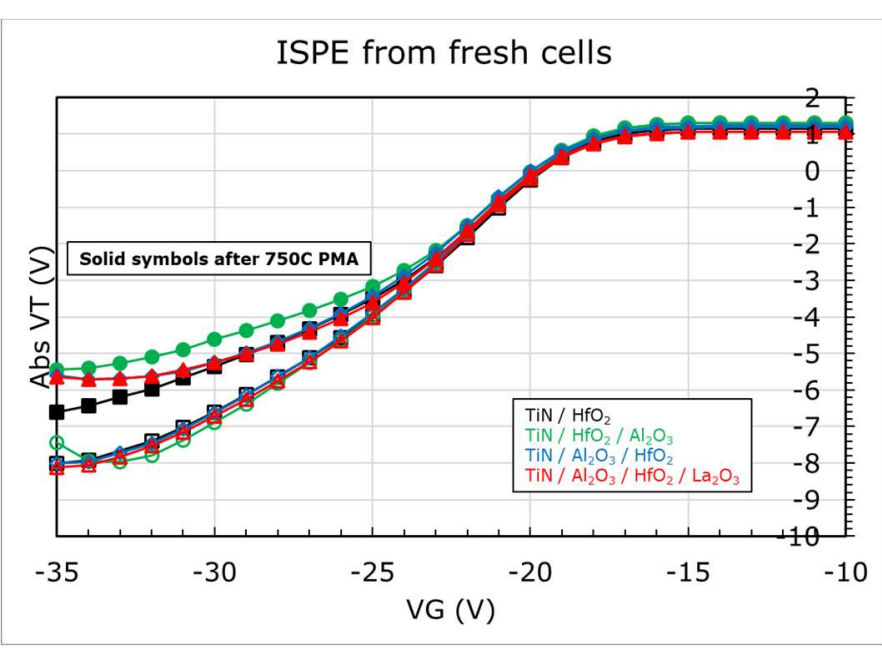

(b)

Figure 17. ISPE of MHONOS, for metal/high-k combinations from Figure 16. (a) Without any PMA; (b) with PMA for 20 min at $750{ }^{\circ} \mathrm{C}$ in $\mathrm{N}_{2}$ ambient.

\section{Conclusions}

We have extracted and studied the shifts in metal work function (i.e., effective work function, eWF), in response to different processing parameters, such as gate electrode and high-k dielectric materials, and variations in annealing conditions. By studying the work function in combination with the erase performance of NAND flash memory, we were able to narrow down the origin of eWF to dipole formation due to (a) interfacial reactions at the metal/high-k interface and/or (b) possible oxygen vacancies driven by structural stabilization at the high- $\mathrm{k} / \mathrm{SiO}_{2}$ interface. It must be noted that based on the above studies, we did not observe fermi level pinning at the metal/high-k interface.

We also verified and validated the negligible impact of dipole on erase performance by studying different dipole forming interlayers in the memory cell. It is clear that the metal WF extraction is convoluted by dipole formation, while the erase performance of a flash memory cell is affected more by the trap profile in the high-k liner than any other factors that cause shift in flat band voltage.

Author Contributions: S.R. was involved in the conceptualization, investigation, formal analysis, visualization, and data curation. The author was also involved in writing the original draft of this manuscript. A.A. was involved in the conceptualization and investigation. L.-A.R. was involved in the conceptualization, supervision, and validation. L.B. was involved in the conceptualization, investigation, validation, and writing-review and editing. The author was also involved in formal analysis and visualization in the early stages of this work. G.K.E.H. was involved in the conceptualization and investigation in the early stages of this work. B.K. and A.B. were involved in the methodology and software development required for the formal analysis in this work. L.N. and J.-P.S. were involved in the investigation and developing material resources for this work. G.V.d.b. and M.R. were involved in conceptualization, project administration, supervision, and writing-review and editing. All authors have read and agreed to the published version of the manuscript.

Funding: This work is supported by IMEC's Industrial Affiliation Program on Storage Memory devices.

Data Availability Statement: Not applicable.

Acknowledgments: Authors acknowledge IMEC's pilot line, the various engineering, process, and support teams. Authors also acknowledge HPSP Inc. for the high-pressure annealing experiment.

Conflicts of Interest: The authors declare no conflict of interest. 


\begin{abstract}
Appendix A
Figure A1 shows the typical capacitance and conductance curves obtained on $70 \times 70 \mu \mathrm{m}^{2}$ capacitors at a frequency of $100 \mathrm{kHz}$. The capacitors were fabricated on a p-doped, $300 \mathrm{~mm}$ $\mathrm{Si}$ substrate with $\mathrm{SiO}_{2}$ bevel. Data is shown for $3 \mathrm{~nm} \mathrm{HfO}$ high-k liner and $\mathrm{Ru}$ gate electrode. The capacitors are sequentially measured at different voltage sweep ranges (i) $1 \mathrm{~V}$ to $-1 \mathrm{~V}$, (ii) $2 \mathrm{~V}$ to $-2 \mathrm{~V}$, (iii) $3 \mathrm{~V}$ to $-3 \mathrm{~V}$. We could notice that there is little impact of the voltage sweep on the hysteresis of the curves. Capacitance data from the $2 \mathrm{~V}$ to $-2 \mathrm{~V}$ voltage sweep range is then used to subsequently extract the flat band voltage, $V_{F B}$.
\end{abstract}

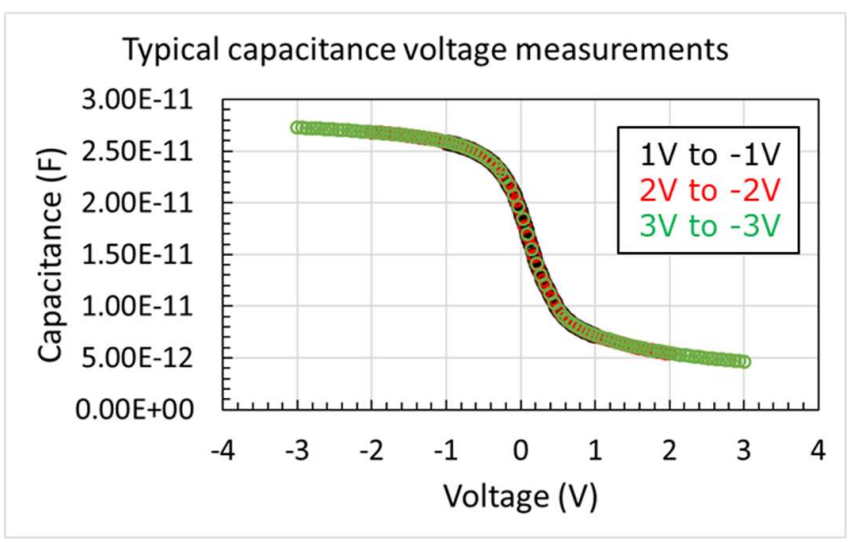

(a)

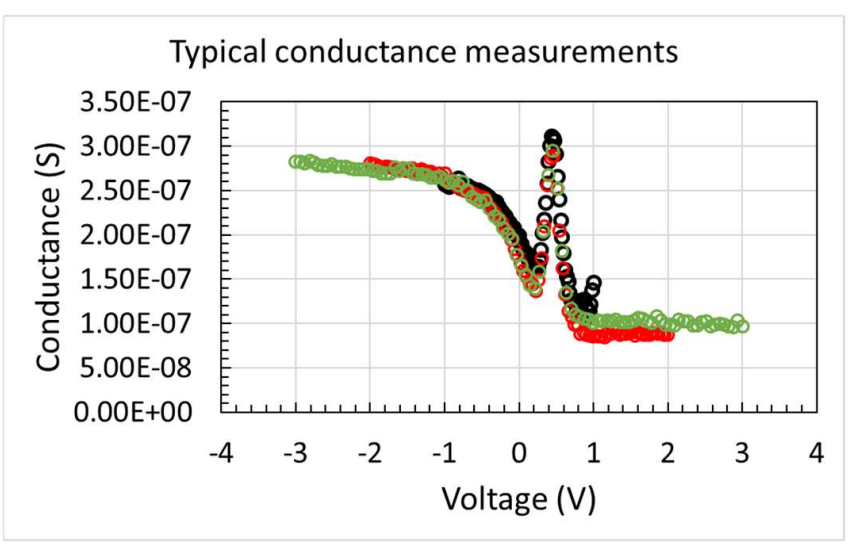

(b)

Figure A1. Typical (a) capacitance and (b) conductance measurements performed in this work. Data shown for Ru/HfO2 combination on $\mathrm{SiO}_{2}$ bevel (slant etch) on a p-type $\mathrm{Si}$ substrate. The capacitors are sequentially measured at different voltage sweep ranges (i) $1 \mathrm{~V}$ to $-1 \mathrm{~V}$, (ii) $2 \mathrm{~V}$ to $-2 \mathrm{~V}$, (iii) $3 \mathrm{~V}$ to $-3 \mathrm{~V}$.

Figure A2 shows the schematic of an automated $V_{F B}$ extraction with a robust and traceable procedure. Test for gate leakage is performed in the measurement routine (not shown) and warnings are issued if any issues are encountered. Only those data with appropriate fit errors are filtered for further analysis. The rest of the analysis follows as discussed in the main article (see page 5 onwards).
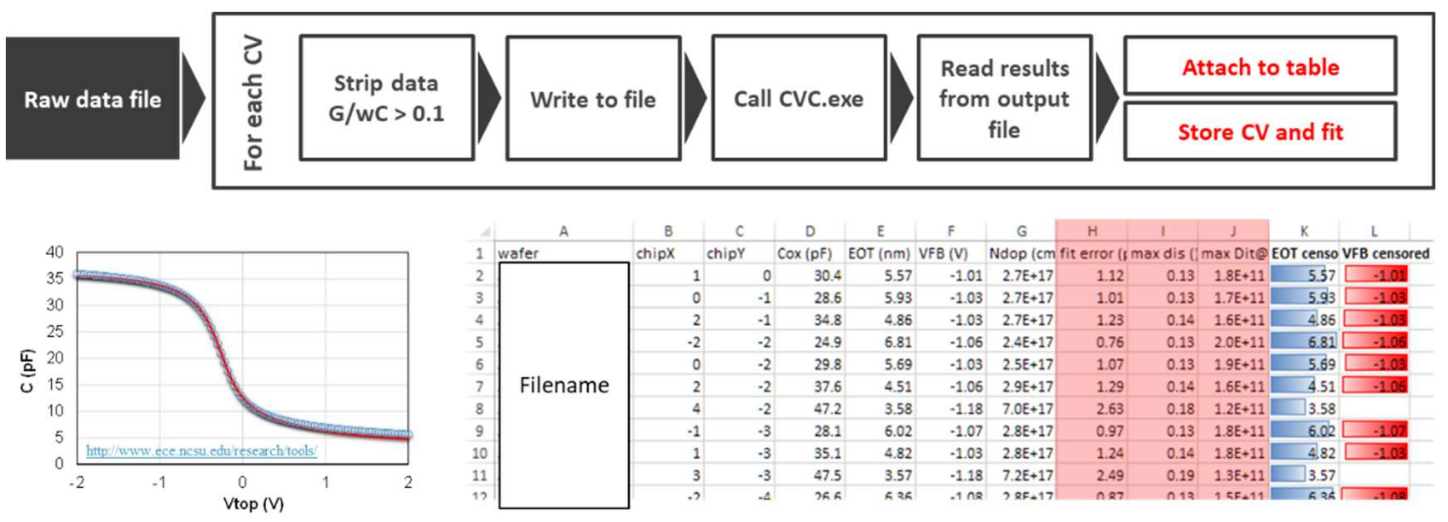

Figure A2. Example procedure of data extraction from measurement.

\title{
References
}

1. Parat, K.; Goda, A. Scaling Trends in NAND Flash. In Proceedings of the IEEE International Electron Devices Meeting (IEDM), San Francisco, CA, USA, 1-5 December 2018; pp. 2.1.1-2.1.4. [CrossRef]

2. Tanaka, H.; Kido, M.; Yahashi, K.; Oomura, M.; Katsumata, R.; Kito, M.; Fukuzumi, Y.; Sato, M.; Nagata, Y.; Matsuoka, Y.; et al. Bit Cost Scalable Technology with Punch and Plug Process for Ultra High Density Flash Memory. In Proceedings of the IEEE Symposium on VLSI Technology, Kyoto, Japan, 12-14 June 2007; pp. 14-15. [CrossRef] 
3. Breuil, L.; El Hajjam, G.K.; Ramesh, S.; Ajaykumar, A.; Arreghini, A.; Zhang, L.; Sebaai, F.; Nyns, L.; Raymaekers, T.; Rosmeulen, M.; et al. Integration of Ruthenium-based Wordline in a 3-D NAND Memory Devices. In Proceedings of the IEEE International Memory Workshop (IMW), Dresden, Germany, 17-20 May 2020; pp. 1-4. [CrossRef]

4. Jeon, S.; Han, J.; Lee, J.; Choi, S.; Hwang, H.; Kim, C. High Work-Function Metal Gate and High-kappaDielectrics for Charge Trap Flash Memory Device Applications. IEEE Trans. Electron Devices 2005, 52, 2654-2659. [CrossRef]

5. Tan, C.-L.; Lavizzari, S.; Blomme, P.; Breuil, L.; Vecchio, G.; Sebaai, F.; Paraschiv, V.; Tao, Z.; Schepers, B.; Nyns, L.; et al. In Depth Analysis of 3D NAND Enablers in Gate Stack Integration and Demonstration in 3D Devices. In Proceedings of the IEEE International Memory Workshop (IMW), Monterey, CA, USA, 14-17 May 2017; pp. 1-4. [CrossRef]

6. Arreghini, A.; Van den Bosch, G.; Kar, G.S.; Van Houdt, J. Ultimate Scaling Projection of Cylindrical 3D SONOS Devices. In Proceedings of the 2012 4th IEEE International Memory Workshop, Milan, Italy, 20-23 May 2012; pp. 1-4. [CrossRef]

7. Charbonnier, M.; Mitard, J.; Leroux, C.; Ghibaudo, G.; Cosnier, V.; Besson, P.; Martin, F.; Reimbold, G. Reliable extraction of metal gate work function by combining two electrical characterization methods. In Proceedings of the ESSDERC 2007-37th European Solid State Device Research Conference, Munich, Germany, 11-13 September 2007; pp. 275-278. [CrossRef]

8. O'Sullivan, B.; Kaushik, V.; Ragnarsson, L.-A.; Onsia, B.; Van Hoornick, N.; Rohr, E.; DeGendt, S.; Heyns, M. Device performance of transistors with high-/spl kappa/ dielectrics using cross-wafer-scaled interface-layer thickness. IEEE Electron Device Lett. 2006, 27, 546-548. [CrossRef]

9. Akiyama, K.; Wang, W.; Mizubayashi, W.; Ikeda, M.; Ota, H.; Nabatame, T.; Toriumi, A. Roles of oxygen vacancy in HfO2/ultrathin $\mathrm{SiO}_{2}$ gate stacks-Comprehensive understanding of VFB roll-off -. In Proceedings of the 2008 Symposium on VLSI Technology, Honolulu, HI, USA, 17-19 June 2008; pp. 80-81. [CrossRef]

10. Kadoshima, M.; Ogawa, A.; Ota, H.; Ikeda, M.; Takahashi, M.; Satake, H.; Nabatame, T.; Toriumi, A. Two Different Mechanisms for Determining Effective Work Function (fm,eff) on High-k—Physical Understanding and Wider Tunability of fm,eff. In Digest of Technical Papers, Proceedings of the 2006 Symposium on VLSI Technology, Honolulu, HI, USA, 13-15 June 2006; IEEE: Piscataway, NJ, USA, 2006; pp. 180-181. [CrossRef]

11. Kamimuta, Y.; Iwamoto, K.; Nunoshige, Y.; Hirano, A.; Mizubayashi, W.; Watanabe, Y.; Migita, S.; Ogawa, A.; Ota, H.; Nabatame, T.; et al. Comprehensive Study of VFB Shift in High-k CMOS-Dipole Formation, Fermi-level Pinning and Oxygen Vacancy Effect. In Proceedings of the IEEE International Electron Devices Meeting, Washington, DC, USA, 10-12 December 2007; pp. 341-344. [CrossRef]

12. Kornblum, L.; Rothschild, J.A.; Kauffmann, Y.; Brener, R.; Eizenberg, M. Band offsets and Fermi level pinning at metal- $\mathrm{Al}_{2} \mathrm{O}_{3}$ interfaces. Phys. Rev. B 2011, 84, 15. [CrossRef]

13. Mönch, W. Metal-semiconductor contacts: Electronic properties. Surf. Sci. 1994, 299-300, 928-944. [CrossRef]

14. Yeo, Y.-C.; King, T.-J.; Hu, C. Metal-dielectric band alignment and its implications for metal gate complementary metal-oxidesemiconductor technology. J. Appl. Phys. 2002, 92, 7266-7271. [CrossRef]

15. Wen, H.-C.; Majhi, P.; Choi, K.; Park, C.; Alshareef, H.N.; Harris, H.R.; Luan, H.; Niimi, H.; Park, H.-B.; Bersuker, G.; et al. Decoupling the Fermi-level pinning effect and intrinsic limitations on p-type effective work function metal electrodes. Microelectron. Eng. 2008, 85, 2-8. [CrossRef]

16. Akasaka, Y.; Nakamura, G.; Shiraishi, K.; Umezawa, N.; Yamabe, K.; Ogawa, O.; Lee, M.; Amiaka, T.; Kasuya, T.; Watanabe, H.; et al. Modified Oxygen Vacancy Induced Fermi Level Pinning Model Extendable to P-Metal Pinning. Jpn. J. Appl. Phys. 2006, 45, L1289-L1292. [CrossRef]

17. Yang, Z.C.; Huang, A.P.; Zheng, X.H.; Xiao, Z.S.; Liu, X.Y.; Zhang, X.W.; Chu, P.K.; Wang, W.W. Fermi-Level Pinning at Metal/High-k Interface Influenced by Electron State Density of Metal Gate. IEEE Electron Device Lett. 2010, 31, 1101-1103. [CrossRef]

18. Kita, K.; Toriumi, A. Origin of electric dipoles formed at high-k/SiO2 interface. Appl. Phys. Lett. 2009, 94, 132902. [CrossRef]

19. Bersuker, G.; Park, C.S.; Wen, H.-C.; Choi, K.; Price, J.; Lysaght, P.; Tseng, H.-H.; Sharia, O.; Demkov, A.; Ryan, J.T.; et al. Origin of the Flatband-Voltage Roll-Off Phenomenon in Metal/High- k Gate Stacks. IEEE Trans. Electron Devices 2010, 57, $2047-2056$. [CrossRef]

20. Iwamoto, K.; Ogawa, A.; Kamimuta, Y.; Watanabe, Y.; Mizubayashi, W.; Migita, S.; Morita, Y.; Takahashi, M.; Ito, H.; Ota, H.; et al. Re-examination of Flat-Band Voltage Shift for High-k MOS Devices. In Proceedings of the 2007 IEEE Symposium on VLSI Technology, Kyoto, Japan, 12-14 June 2007; pp. 70-71. [CrossRef]

21. Charbonnier, M.; Leroux, C.; Cosnier, V.; Besson, P.; Martinez, E.; Benedetto, N.; Licitra, C.; Rochat, N.; Gaumer, C.; Kaja, K.; et al. Measurement of Dipoles/Roll-Off /Work Functions by Coupling CV and IPE and Study of Their Dependence on Fabrication Process. IEEE Trans. Electron Devices 2010, 57, 1809-1819. [CrossRef]

22. Padovani, A.; Kaczer, B.; Pesic, M.; Belmonte, A.; Popovici, M.; Nyns, L.; Linten, D.; Afanas'Ev, V.V.; Shlyakhov, I.; Lee, Y.; et al. A Sensitivity Map-Based Approach to Profile Defects in MIM Capacitors From I-V, C-V, and G-V Measurements. IEEE Trans. Electron Devices 2019, 66, 1892-1898. [CrossRef]

23. Kaushik, V.; O'Sullivan, B.; Pourtois, G.; Van Hoornick, N.; Delabie, A.; Van Elshocht, S.; Deweerd, W.; Schram, T.; Pantisano, L.; Rohr, E.; et al. Estimation of fixed charge densities in hafnium-silicate gate dielectrics. IEEE Trans. Electron Devices 2006, 53, 2627-2633. [CrossRef]

24. Jha, R.; Gurganos, J.; Kim, Y.; Choi, R.; Lee, J.; Misra, V. A Capacitance-Based Methodology for Work Function Extraction of Metals on High-kappa. IEEE Electron Device Lett. 2004, 25, 420-423. [CrossRef] 
25. Hauser, J.R. North Carolina State Umiversity's CVC. Computer Analysis Software, 1999.

26. Park, J.-Y.; Yun, D.-H.; Kim, S.-Y.; Choi, Y.-K. Suppression of Self-Heating Effects in 3-D V-NAND Flash Memory Using a Plugged Pillar-Shaped Heat Sink. IEEE Electron Device Lett. 2019, 40, 212-215. [CrossRef]

27. Calzolari, A.; Catellani, A. Controlling the TiN Electrode Work Function at the Atomistic Level: A First Principles Investigation. IEEE Access 2020, 8, 156308-156313. [CrossRef]

28. Wen, H.-C.; Choi, R.; Brown, G.; BosckeBoscke, T.; Matthews, K.; Harris, H.; Choi, K.; Alshareef, H.N.; Luan, H.; Bersuker, G.; et al. Comparison of effective work function extraction methods using capacitance and current measurement techniques. IEEE Electron Device Lett. 2006, 27, 598-601. [CrossRef]

29. Park, K.J.; Doub, J.M.; Gougousi, T.; Parsons, G. Microcontact patterning of ruthenium gate electrodes by selective area atomic layer deposition. Appl. Phys. Lett. 2005, 86, 051903. [CrossRef]

30. Pantisano, L.; Schram, T.; Li, Z.; Lisoni, J.G.; Pourtois, G.; De Gendt, S.; Brunco, D.P.; Akheyar, A.; Afanas'Ev, V.V.; Shamuilia, S.; et al. Ruthenium gate electrodes on $\mathrm{SiO}_{2}$ and $\mathrm{HfO}_{2}$ : Sensitivity to hydrogen and oxygen ambients. Appl. Phys. Lett. 2006, 88, 243514. [CrossRef]

31. Afanas'Ev, V.V.; Stesmans, A. Internal photoemission at interfaces of high-K insulators with semiconductors and metals. J. Appl. Phys. 2007, 102, 81301. [CrossRef]

32. Ramesh, S.; Ajaykumar, A.; Bastos, J.; Breuil, L.; Arreghini, A.; Nyns, L.; Soulié, J.-P.; Ragnarsson, L.-Å.; Schleicher, F.; Jossart, N.; et al. Erase Behavior of Charge Trap Flash Memory Devices using High-k Dielectric as Blocking Oxide Liner. In Proceedings of the IEEE Semiconductor Interface Specialists Conference, San Diego, CA, USA, 6-8 December 2020.

33. Chou, A.I.; Lai, K.; Kumar, K.; Chowdhury, P.; Lee, J.C. Modeling of stress-induced leakage current in ultrathin oxides with the trap-assisted tunneling mechanism. Appl. Phys. Lett. 1997, 70, 3407-3409. [CrossRef]

34. Iwamoto, K.; Kamimuta, Y.; Ogawa, A.; Watanabe, Y.; Migita, S.; Mizubayashi, W.; Morita, Y.; Takahashi, M.; Ota, H.; Nabatame, T.; et al. Experimental evidence for the flatband voltage shift of high-k metal-oxide-semiconductor devices due to the dipole formation at the high-k/SiO2 interface. Appl. Phys. Lett. 2008, 92, 132907. [CrossRef]

35. Suarez-Segovia, C.; Caubet, P.; Joseph, V.; Gourhant, O.; Romano, G.; Domengie, F.; Ghibaudo, G. Effective Work Function Shift Induced by TiN Sacrificial Metal Gates as a Function of Their Thickness and Composition in $14 \mathrm{~nm}$ NMOS devices. In Proceedings of the International Conference on Solid State Devices and Materials, Ibaraki, Japan, 8-11 September 2014. [CrossRef]

36. Bersch, E.; Di, M.; Consiglio, S.; Clark, R.D.; Leusink, G.J.; Diebold, A.C. Complete band offset characterization of the $\mathrm{HfO}_{2} / \mathrm{SiO}_{2} / \mathrm{Si}$ stack using charge corrected x-ray photoelectron spectroscopy. J. Appl. Phys. 2010, 107, 043702. [CrossRef]

37. Wang, X.; Han, K.; Wang, W.; Chen, S.; Ma, X.; Chen, D.; Zhang, J.; Du, J.; Xiong, Y.; Huang, A. Physical origin of dipole formation at high-k/SiO 2 interface in metal-oxide-semiconductor device with high-k/metal gate structure. Appl. Phys. Lett. 2010, 96, 152907. [CrossRef]

38. Sivasubramani, P.; Boscke, T.S.; Huang, J.; Young, C.D.; Kirsch, P.D.; Krishnan, S.A.; Quevedo-Lopez, M.A.; Govindarajan, S.; Ju, B.S.; Harris, H.R.; et al. Dipole Moment Model Explaining nFET Vt Tuning Utilizing La, Sc, Er, and Sr Doped HfSiON Dielectrics. In Proceedings of the 2007 IEEE Symposium on VLSI Technology, Kyoto, Japan, 12-14 June 2007; pp. 68-69. [CrossRef]

39. Zheng, X.H.; Huang, A.P.; Xiao, Z.S.; Yang, Z.C.; Wang, M.; Zhang, X.W.; Wang, W.W.; Chu, P.K. Origin of flat-band voltage sharp roll-off in metal gate/high-k/ultrathin-SiO2/Si p-channel metal-oxide-semiconductor stacks. Appl. Phys. Lett. 2010, $97,132908$. [CrossRef]

40. Sharia, O.; Demkov, A.A.; Bersuker, G.; Lee, B.H. Theoretical study of the insulator/insulator interface: Band alignment at theSiO $2 / \mathrm{HfO}_{2}$ junction. Phys. Rev. B 2007, 75, 035306. [CrossRef]

41. Franco, J.; Wu, Z.; Rzepa, G.; Vandooren, A.; Arimura, H.; Claes, D.; Horiguchi, N.; Collaert, N.; Linten, D.; Grasser, T.; et al. Low Thermal Budget Dual-Dipole Gate Stacks Engineered for Sufficient BTI Reliability in Novel Integration Schemes. In Proceedings of the 2019 Electron Devices Technology and Manufacturing Conference (EDTM), Singapore, 12-15 March 2019; pp. $215-217$. [CrossRef]

42. Arimura, H.; Sioncke, S.; Cott, D.; Mitard, J.; Conard, T.; Vanherle, W.; Loo, R.; Favia, P.; Bender, H.; Meersschaut, J.; et al. Ge nFET with high electron mobility and superior PBTI reliability enabled by monolayer-Si surface passivation and La-induced interface dipole formation. In Proceedings of the 2015 IEEE International Electron Devices Meeting (IEDM), Washington, DC, USA, 7-9 December 2015; pp. 21.6.1-21.6.4. [CrossRef]

43. Choi, K.; Wen, H.-C.; Bersuker, G.; Harris, R.; Lee, B.H. Mechanism of flatband voltage roll-off studied with Al2O3 film deposited on terraced oxide. Appl. Phys. Lett. 2008, 93, 133506. [CrossRef]

44. Yamamoto, Y.; Kita, K.; Kyuno, K.; Toriumi, A. Study of La-Induced Flat Band Voltage Shift in Metal/HfLaOx/SiO2/Si Capacitors. Jpn. J. Appl. Phys. 2007, 46, 7251-7255. [CrossRef]

45. Arimura, H.; Cott, D.; Loo, R.; Vanherle, W.; Xie, Q.; Tang, F.; Jiang, X.; Franco, J.; Sioncke, S.; Ragnarsson, L.-Å.; et al. Si-passivated Ge nMOS gate stack with low Dit and dipole-induced superior PBTI reliability using 3D-compatible ALD caps and high-pressure anneal. In Proceedings of the 2016 IEEE International Electron Devices Meeting (IEDM), San Francisco, CA, USA, 3-7 December 2016; pp. 33.4.1-33.4.4. [CrossRef]

46. Vais, A.; Franco, J.; Lin, D.; Putcha, V.; Sioncke, S.; Mocuta, A.; Collaert, N.; Thean, A.; De Meyer, K. On the distribution of oxide defect levels in $\mathrm{Al}_{2} \mathrm{O}_{3}$ and $\mathrm{HfO}_{2}$ high-k dielectrics deposited on InGaAs metal-oxide-semiconductor devices studied by capacitance-voltage hysteresis. J. Appl. Phys. 2017, 121, 144504. [CrossRef] 